Revista Iberoamericana, Vol. LXXI, Núm. 211, Abril-Junio 2005, 471-483

\title{
LA ALEGORÍA JURÍDICA EN EL SONETO 174 DE SOR JUANA
}

\author{
POR \\ HERNÁN FELDMAN \\ Indiana University
}

\begin{abstract}
[...] un jurista y un abogado mediocres están lejos, respectivamente, de la competencia de un Aulo Cascelio y de la facundia de un Mesala, si bien esto no quita que gocen de estima. Pero a los poetas no les permitieron ser mediocres ni los hombres, ni los dioses, ni las estanterías de los libreros.
\end{abstract}

Horacio, "Arte Poética”

El enigma que gira alrededor de la fuerza legislativa de la palabra escrita constituye un desafío fascinante. Y para quienes hemos dedicado una porción de nuestras vidas al estudio del derecho, esta fascinación aumenta cuando comprobamos que aquellas resonancias enigmáticas percibidas en nuestras lecturas de literatura áurea han sido definitivamente transformadas en una presencia tangible gracias a la obra de Roberto González Echevarría. Porque cuando el crítico cubano concentra su trabajo en la presencia del discurso jurídico en el género picaresco y en las crónicas coloniales, podemos apreciar en toda su dimensión que la actividad misma de escribir implicaba un inexorable parentesco con la producción cultural de quienes en aquellos tiempos sabían hacerlo, es decir, los letrados. ${ }^{1}$ Con un rigor crítico magistral, entonces, González Echevarría nos termina convenciendo de que el oficio de la escritura en el Siglo de Oro a ambos lados del Océano Atlántico no podía estar sino íntimamente supeditado a las convenciones del derecho. Y si bien esto podría no sorprender tanto en un ambiente dominado por hombres cuya actividad oscilaba entre la conquista por medios violentos y la ratificación de las usurpaciones por medios escritos, la producción e interpretación de la letra de la ley en cabeza de una mujer empieza a enriquecer el panorama en forma exponencial. En este sentido, es Rosa Perelmuter Pérez quien llega a una conclusión tan certera como inquietante para el caso de la famosa letrada mexicana que nos ocupa. La "Respuesta a Sor Filotea” de Sor Juana Inés de la Cruz, dice Perelmuter Pérez, despliega “un discurso que encuadra perfectamente en la línea de la oratoria forense” (148).

\footnotetext{
${ }^{1}$ No se nos puede escapar que la palabra "letrado" se refiere a la persona que sabe leer y escribir como así también a la persona que es jurista de profesión. "Letrado, el que professa letras, y hanse alçado con este nombre los juristas abogados” ( Covarrubias 763).
} 
Si la brillante construcción retórica de la respuesta que Sor Juana edifica con mano de letrado diestro no cubriera los extremos del onus probandi, la cantidad y diversidad de obras que Ermilo Abreu Gómez adjudicó a la biblioteca sorjuanina no dejan dudas acerca de sus lecturas de los maestros de la retórica forense. Sin ir más lejos, Cicerón es uno de los autores cuya presencia en la biblioteca de marras ha resultado indudable. Además, la existencia en ella de diferentes libros de derecho puede ser más que inferida, no sólo por ser el derecho objeto de mención en la "Respuesta a Sor Filotea" como una de las ciencias súbditas de la teología, sino también a la luz del estudio de Josefina Muriel sobre las bibliotecas de las mujeres distinguidas de la época, a quienes Sor Juana superaba ampliamente en recursos bibliográficos. ${ }^{2}$

Así las cosas, vemos que una conquista signada por el escrupuloso legalismo desemboca en diferentes manifestaciones literarias que, nutriéndose de los maestros clásicos de la retórica, comparten una voz cuasijurídica común. La prosa de la época, en efecto, navega frecuentemente en un mar poblado de convenciones jurídicas. Por una parte, no podía ser de otro modo, ya que el precursor mismo de la prosa castellana fue también el protagonista de la elaboración y compilación de Las siete partidas. Pero por otra parte, en el caso de Sor Juana, estas convenciones debieron constituirse en requisito sine qua non para una escritora que, dentro de un ámbito regulado por el rígido catolicismo contrarreformista, frecuentemente debía refutar acusaciones cuidándose de no provocar la cólera de la jerarquía eclesiástica masculina. Existe sin lugar a dudas un marco de debate teológico-jurídico en el que se inscribe la defensa de Sor Juana ante las paternalistas reprimendas de sus superiores en la cadena de mandos del culto católico. ${ }^{3}$

Si bien la prosa da lugar a estas intrusiones de la letra forense, la tradición poética abordó otros temas y utilizó una voz completamente diferente. No podemos afirmar, entonces, que las formas jurídicas fueran necesarias o propicias para fortalecer los cimientos retóricos de una poesía, y mucho menos aún en sonetos de tema amoroso. Sin embargo, Georgina Sabat de Rivers nos sorprende con una excelente exposición de los veintiún sonetos sorjuaninos en la que insinúa la existencia de un diálogo entre institutos del derecho y el poema endecasílabo. Usando el lenguaje de Sor Juana, Sabat de Rivers utiliza la afortunada construcción jurídico-amorosa “casuística del amor” y, además, señala que fue un notario, Giacomo da Lentino, quien inauguró la novedosa práctica poética del soneto. En su monumental trabajo sobre Sor Juana, Octavio Paz afirma también que "[e]ra inevitable que el vocabulario jurídico de la época sirviese para expresar las nuevas relaciones de fidelidad amorosa” (262). Y al estudiar la obra de Paz sobre Sor Juana, Enrico Mario Santí abre a su vez una brecha inexplorada que explota eficazmente el concepto jurídico de la restitución, hilo conductor del soneto que prologa la primera

\footnotetext{
2 "No faltaban, y estuvieron al alcance de las mujeres, los libros de geografía, astronomía y también obras de derecho civil eclesiástico y las Leyes de Indias" (Muriel 172).

${ }^{3}$ Sin duda, las relaciones entre el derecho y la religión no nacen con el catolicismo contrarreformista, sino que se pueden remontar hasta el Código de Hammurabi, pasando por la Torah (especialmente los libros del Éxodo, Deuteronomio, Números y Levítico) y el Talmud, hasta el Corán y el Código de Derecho Canónico. Estos lazos son al mismo tiempo múltiples y fascinantes. Lamentablemente, resulta imposible hacerles justicia en un trabajo de esta extensión.
} 
edición de Inundación Castálida. Pero a más de la mera existencia del término “restitución” en el soneto "El hijo que la esclava ha concebido”, lo significativo del caso es la función que desempeña dicha construcción jurídica. En este sentido, Santí dice que "[e]l poema construye, a partir del uso de la restitución como concepto central, toda una serie de analogías legales basadas todas en el código del amor cortés” (225).

Estas analogías jurídicas rimadas con el objeto de desentrañar las alternativas del amor me conducen a presentar otro soneto que Tarcisio Herrera Zapién asegura ha sido “muy poco citado" (34), y que corresponde al número 174 de la edición que Alfonso Méndez Plancarte realiza de las obras completas del Fénix de América. A continuación, el texto del soneto:

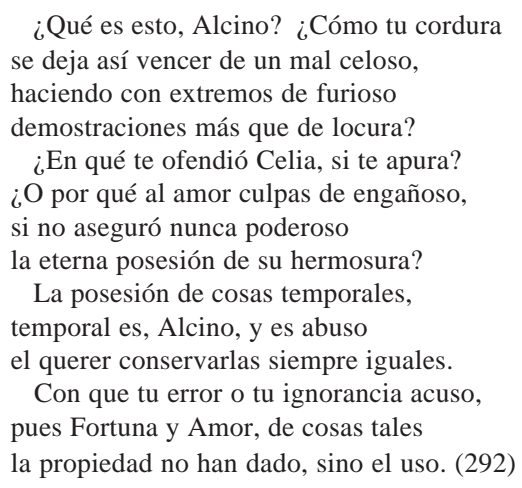

El lugar que el soneto ha ocupado tradicionalmente ha sido el de “amor y discreción”, pero la importante labor reclasificatoria de Sabat de Rivers lo ubica como correspondiente a poemas que reflejan un concepto heterodoxo del amor y, dentro de esta categoría, a aquellos que tratan su temporalidad. Más específicamente, Sabat de Rivers toca la punta del iceberg que anuncia la presencia de la lógica jurídica del soneto cuando señala que las palabras “uso” y "propiedad” están inscriptas en el marco jurídico-mercantil, y que son utilizadas por Sor Juana para explicar el amor. ${ }^{4}$

El propósito de este trabajo es demostrar que en el soneto 174, bajo la exposición ostensible de la temporalidad del amor, subyace ya no una curiosidad lexicográfica, sino un nutrido mapa jurídico que nos invita a una lectura paralela de la temática. A la par de la voz estrictamente poética, en efecto, existe una voz que asume un rol forense, hipótesis abonada en principio por la sucesión de preguntas, piedra angular de la dinámica tribunalicia. Inversamente al Lazarillo de Tormes, en el que el lector no tiene acceso a las preguntas que motivan la deposición de Lázaro, en nuestro “caso” el lector conoce las preguntas a través de las cuales sólo puede inferir los hechos que motivan la conducta celosa de Alcino. La voz forense no circunscribe su rol al interrogatorio de los cuartetos:

4 “[...] Amor y Fortuna (la alegoría de la rueda que todo lo cambia) tienen en común dar sólo el uso de las cosas temporales, no la propiedad, es decir, la posesión legal” (Sabat de Rivers 438). 
en el primer terceto continúa con un alegato y en el segundo con una acusación. De esta manera, podemos extender la noción bakhtiniana de heteroglosia más allá de los límites estrictamente novelísticos y sugerir que Sor Juana trabaja con dos voces que sostienen un diálogo revelador del aparato jurídico que sojuzgaba a la mujer de la época colonial. ${ }^{5}$ Veamos entonces cómo trabajan estas voces paralelas.

En principio, a los conceptos de "propiedad” y “uso” que señalaba Sabat de Rivers debemos sumar la palabra “posesión”, que también aparece en dos ocasiones en el poema. La tríada propiedad-uso-posesión, en efecto, nos sitúa en una rama del derecho que se ocupa de los derechos reales. Los derechos reales o in rem son aquellos que regulan las relaciones jurídicas que se establecen entre una persona y una cosa. Digamos entonces que el campo específico en el que se despliega el andamiaje retórico del poema son estos derechos reales en los que concurren sujeto y objeto mediados por uno o más derechos. Principiaremos entonces por tratar la relación jurídica, seguiremos con el sujeto y terminaremos con la cosa.

Pero para hacerlo deberemos tomar en cuenta que en el tiempo de Sor Juana Las siete partidas eran la fuente del derecho español con más alta jerarquía. Y para a su vez entender acabadamente la legislación, como dice Gaspar Melchor de Jovellanos, debemos convocar el auxilio de la historia. En su estudio histórico de las leyes hispanas, entonces, Jovellanos nos asegura que los jurisconsultos que realizaron la compilación alfonsí siguieron dos líneas de acción. Por un lado, introdujeron por primera vez el derecho canónico en la legislación española. Por el otro, volvieron al derecho vigente durante la época en que Hispania era una provincia del Imperio Romano: "copiaron en [la compilación], no sólo las leyes de Roma, sino también las opiniones de los jurisconsultos de Italia” (95). Resulta insoslayable, entonces, interpretar los derechos reales que Sor Juana ensambla poéticamente a la luz de la regulación romana. ${ }^{6}$

En el derecho romano, los derechos reales estaban revestidos de un formalismo extremo y requerían la concurrencia de dos elementos para su existencia: el modo de adquisición y el título. Había una cantidad taxativa tanto de modos de adquisición como de títulos y las partes no podían crear modalidades o títulos nuevos. Para mencionar sólo algunos modos de adquisición de la propiedad, una heredad se podía adquirir por la compra, por la transmisión hereditaria, por una donación o por la posesión pacífica continuada de la misma por un período de tiempo. Una vez adquirida la propiedad, el propietario obtenía un título probatorio de su derecho oponible erga omnes, es decir, que la sociedad toda tenía la obligación pasivamente universal de respetar la titularidad del dueño. El título, en definitiva, era un documento inscripto en un registro público que explicaba la relación del sujeto con la cosa, en nuestro ejemplo, la propiedad. Verdad es que la propiedad no es el único derecho real, sino que también existen además el uso, el

\footnotetext{
${ }^{5}$ En este sentido, es importante destacar que Bakhtin sostenía que la poesía era uno de los lenguajes desprovistos de la carga ideológica coyuntural que sí se ve en la novela (34). Evidentemente, ésta es una divisoria más que Sor Juana ha traspasado.

${ }^{6}$ Carlos Fuentes corrobora y va aún más lejos que Jovellanos con la siguiente afirmación: “The Roman legalistic tradition is one of the strongest components in Latin American culture: from Cortés to Zapata, we only believe in what is written down and codified” (González Echevarría 1).
} 
usufructo, la servidumbre, la hipoteca o la anticresis, para mencionar algunos de ellos. Sin embargo, la importancia de la propiedad estriba en que la misma tiene un valor emblemático dentro de los derechos reales. En efecto, la manifestación suprema de la cadena semánticojurídica es el dominium, del cual se derivan los demás derechos reales.

En la regulación romana, tres beneficios derivaban del derecho de propiedad o dominium: el uso, el fruto y el abuso. La titularidad de estos dos primeros derechos en forma aislada era bastante precaria. El usuario y el usufructuario podían usar la cosa o usarla para percibir sus frutos, pero estaban siempre supeditados al título del propietario de la cosa, que podía disponer de ella transfiriendo el uso/usufructo a otro usuario/ usufructuario o reservándolo para sí mismo. El propietario, en definitiva, era el sujeto en el que recaían los dos beneficios en forma simultánea (usar y percibir los frutos) además del abuso, derecho exclusivo e indelegable del dueño. El usuario, entonces, al serle quitado el uso de la cosa por el propietario, no tiene derecho a reclamar la devolución de la misma como parece pretender Alcino en el poema. Pero, ¿¿cuáles son los términos del diálogo que establecen las voces lírica y forense en cuanto a la relación jurídica aplicable al caso?

En el primer terceto, la voz poética simplemente explica a Alcino que se encuentra en un error y que la pretensión de continuar con la relación amorosa constituye un exceso de su parte. La voz forense, sin embargo, insinúa algo similar basándose en los tres beneficios derivados de la propiedad romana. Aparece así en el soneto la noción jurídica exclusiva del propietario: el abuso. La posesión de la hermosura del amor, entonces, es meramente temporal, y es abusivo pretender un status quo que conlleve al mero usuario a perpetuarse en un dominio que no le corresponde. Si bien la voz poética en el segundo terceto continúa el reproche a Alcino y le manifiesta que no puede obligar a Celia a mantener la relación amorosa, surge al mismo tiempo una voz forense que utiliza tecnicismos jurídicos que veremos más adelante para demostrar, entre otras cosas, que Alcino no tiene título de propietario, sino de usuario. En definitiva, la voz poética sugiere que el amor humano no da seguridades porque la carne envejece y perece, y por consiguiente la posesión corre idéntica suerte. La voz forense, sin embargo, profundiza esta idea a través de la concepción estrictamente jurídica de la posesión, que se constituye en metáfora de lo provisorio. Así las cosas, resulta fundamental descubrir por qué la posesión sirve de enunciado jurídico-poético para ilustrar la calidad efímera del amor.

Es oportuno recordar entonces que estamos trabajando con una tríada formada por los conceptos “propiedad”, “uso” y “posesión”, que pertenecen al campo de los derechos reales. Es necesario aclarar, asimismo, que tales conceptos responden a categorías diferentes dentro de dicho campo. En efecto, mientras que la propiedad y el uso son derechos reales per se, la posesión es solamente un modo de adquisición del cual pueden derivar derechos reales o no. La posesión es, en suma, el hecho -y no el derecho-de tener una cosa corporal, reteniéndola materialmente, con la voluntad de poseerla, y disponer de ella como lo haría un propietario. En la regulación romana existían dos elementos que hacían posible la posesión; corpore, el elemento material que consiste en tener la cosa en su poder, y animo, que es el elemento intencional, también llamado animus domini. Como vemos, la posesión -por sí sola- es una relación de hecho entre el individuo y la cosa que, prima facie, nada dice sobre el título: en efecto, el ladrón también es poseedor de la cosa 
robada. ${ }^{7}$ Como pudimos apreciar anteriormente, los derechos reales requieren de modo de adquisición y de título. Alcino adquirió el título de usuario a través del modo de adquisición llamado posesión, pero no se constituyó en propietario porque la "posesión” por sí sola no le garantiza el título de propiedad: para ello deben concurrir otras condiciones que tienen que ver con la cosa adquirida y que trataremos en más detalle al ocuparnos del objeto de la relación jurídica.

A esta altura comprendemos claramente que la elección que la poeta hace de estos vocablos no es casual. Los argumentos de la voz forense tampoco surgen gratuitamente, sino que son una respuesta a un reclamo de Alcino: en efecto, el celoso pretende que se le reconozca un derecho de propiedad. La abogada de Celia prueba que el título que Alcino ha adquirido a través de la posesión es el de usuario, y le marca repetidas veces que él ha estado en mera posesión de una cosa temporal. Más aún, la voz defensora devenida en fiscal agudiza la brecha entre uso y propiedad al concebir el absurdo de la "posesión eterna”, lo cual constituye un oxímoron jurídico. Efectivamente, la naturaleza misma de la posesión implica una situación jurídica instrumental -y no sustancial- que puede fenecer en cualquier momento sin intervención positiva del usuario.

Como hemos visto, los derechos reales consistían en la relación jurídica entre un sujeto y una cosa. Habiéndonos dedicado hasta ahora a la relación jurídica (modo de adquisición: posesión; título; propietario vs. usuario), nos proponemos de aquí en más abocarnos a analizar la acusación que la voz forense dirige al sujeto de dicha relación, esto es, a Alcino. Es interesante señalar que el "error o ignorancia” no se advierte, no se nota, no se repara. Se acusa.

Esta decisión léxica inscribe aún más al poema dentro de la trama jurídica que intentamos dilucidar. Evidentemente, la acusación es la actividad jurisdiccional ejercida por el ministerio público fiscal, investida en cabeza de los "hombres necios" que acusan en la "Redondilla 92" sorjuanina, ante quienes la voz poética aboga en defensa de las mujeres. Pero en el caso de nuestro soneto los papeles se invierten: la acusación es ahora formulada por una voz poética forense que presumo femenina y que acusa a un sujeto masculino. En este sentido, la tradición jurídica romano-hispánica es claramente hostil a la aceptación de mujeres en cargos públicos cuyas prerrogativas incluyan la acusación. En el Fuero Real de Alfonso el Sabio, por ejemplo, las mujeres estaban excluidas de este ministerio acusador. ${ }^{8}$ La Partida 7, Título 1, Ley 2 también se hará eco de este sistema por

7 "Hay posesión de hecho y posesión de hecho y voluntad. La posesión de hecho no es más que una simple tenencia de una cosa que está en nuestras manos [...] no puede llamarse verdadera posesión. La posesión de hecho y de voluntad es la tenencia de una cosa con ánimo de escluir a los otros de su uso..." (Alfonso X, 3/636).

${ }^{8}$ En el derecho del Fuero Real, Título 20 "De las acusaciones e de las pesquisas”, Ley 2, se prescribe lo siguiente: "Defendemos que ninguna mugier, nin omne sin edat cumplida, nin alcalde, nin meri(no), ni otro ninguno que tenga officio de iusticia mientre que el oficio touiere, ni omne que sea echado de la uilla o de la tierra mientre que fuere echado, nin omne que tomó auer pora acusar a otro por non accusar, nin iudío, nin moro, nin erege, nin omne aforado, nin fiio a padre, nin padre a fiio, nin aquellos que sean de heredar unos a otros, nin sieruo, nin omne que fue echado a aquel qui lo crio o lo dio a criar, nin omne que dixo falso testimonio, nin omne que fuere acusado mientre que lo fuere, nin omne que acusare a II e non fuere afinada la acusatión por iuyzio e quier accusar el tercero, nin omne muy pobre que non aya ualía de L morabedís fuera ende si acusare so egual, nin 
el que la mujer no puede acusar en juicio sino en ciertos casos extremos. Sin embargo, a contrapelo de esta arraigada tradición, la poeta inviste a la voz forense con esta alta dignidad y la hace desempeñar sus funciones con maestría.

Entre las acusaciones que formula la voz forense tenemos al ya mencionado error o ignorancia de Alcino. Pero si nos remitimos al primer cuarteto, vemos claramente que la abogada también está poniendo en duda la competencia racional del enamorado, cuando su "cordura / se deja así vencer de un mal celoso". Es que si bien el poema todo es una respuesta poético-jurídica a los reclamos de Alcino, dicha respuesta impugna actos jurídicos cuyo sujeto activo es Alcino pero que corresponden a dos momentos diferentes. Por un lado, el error o ignorancia se refiere al momento en el que Alcino consigue el favor amoroso de Celia, suponiéndose propietario. Por el otro, la locura de Alcino se refiere a sus actos en un segundo momento: una vez que el vínculo amoroso se disolvió y se inicia el reclamo.

A pesar de que las impugnaciones de la voz forense se refieren a dos momentos diferentes, ambas se inscriben en la teoría general de los actos jurídicos. En la tradición jurídica del derecho continental, el aspecto interno de la voluntad posee, siguiendo cierto andamiaje escolástico, tres elementos: discernimiento, intención y libertad. Para que un acto se repute válido estos tres elementos deben concurrir, sumados a la manifestación externa de la voluntad. ${ }^{9}$ La contracara de dichos atributos internos son sus vicios que, en ciertas circunstancias, exoneran al sujeto de los efectos de dicho acto. Estos vicios son la incapacidad (minusvalía mental, minoridad), el error o ignorancia, y la violencia.

En el soneto, entonces, la voz poética deja claro que Alcino, por un lado, se equivoca en pretender petrificar el fluir del Amor y la Fortuna y, por el otro, le advierte que sus reclamos se corresponden con los de una persona loca de celos. Paralelamente, tanto al hacerse mención del error o ignorancia como de la locura, el texto jurídico subyacente pone de manifiesto dos vicios de las potencias volitivas llamadas intención y discernimiento. Pero, ¿cómo afectan estos vicios el reclamo de Alcino? O, para decirlo de otra manera, ¿cómo hace la voz forense para disponer estratégicamente estos vicios de modo y manera que el reclamo de Alcino quede insatisfecho? Para tratar este tema debemos abordar la forma y el fondo del reclamo separadamente.

El fondo o el contenido del reclamo tiene que incluir los hechos que motivan el mismo, por lo cual esta petición tiene que realizar una mirada necesariamente retrospectiva. Comenzaremos entonces con el fondo del reclamo para respetar la cronología de los dos momentos antes mencionados, es decir, el concurso amoroso en primer término y la acción

omne que sea dado por malo por iuyzio sobre algun fecho, non puedan accusar a otro ninguno sobre cosa ninguna; pero si alguno les fiziere alguna cosa desaguisada o a ellos o a otri por que aya derecho de lo demandar por tal fecho, puédanlo accusar si quisieren. Otrosí queremos que todos estos sobredichos puedan accusar a otri sobre cosa que sea contra rey o contra su sennorío o contra sus derechos o contra la fe de Sancta Eglesia, fuera ende en el que non á edat que non puede accusar en ninguna manera” (Alfonso X, 2/475-76).

9 “Canon 1101. § 1. El consentimiento interno de la voluntad se presume que está conforme con las palabras o signos empleados al celebrar el matrimonio. §2. Pero si uno de los contrayentes, o ambos, excluye con un acto positivo de la voluntad el matrimonio mismo, o un elemento esencial del matrimonio o una propiedad esencial, contrae inválidamente” (Benlloch Poveda 497). 
de reclamar en sí en segundo lugar. ${ }^{10}$ ¿Cuál es la exposición circunstanciada de los hechos según Alcino? Alcino poseyó a Celia y ella ahora no lo reconoce como dueño. La abogada no disputa esta relación de los hechos. Ahora, ¿cuál es el derecho aplicable? Alcino puede haber actuado teniendo en miras la adquisición de la propiedad de Celia. Aquí sí hay disputa: la abogada indica que la intención de los actos de Alcino adolecía del vicio denominado en la jerga jurídica como "error o ignorancia”. A esta altura ya no puede sorprendernos el saber que la construcción "error o ignorancia” que usa la voz forense se encuentra presente en el derecho de partidas alfonsí, el derecho canónico y en diversos cuerpos jurídicos actuales para aludir al viciamiento de la intención del sujeto en sus diversas transacciones. "Errare humanum est”, podríamos decir, pero lo importante es determinar las consecuencias jurídicas del error en el que incurre el tan humano Alcino.

En el derecho romano, el error básicamente puede consistir en la ignorancia de un hecho o estar equivocado sobre el derecho aplicable. El error de hecho puede ser excusable, en tanto que el error de derecho no. Como vimos, en el momento de la transacción amorosa entre Alcino y Celia, el primero parece haber tenido en miras la adquisición de un derecho de propiedad y, so color de ataque de celos, decide iniciar acción reivindicatoria. ¿Es excusable el error que vicia la intención de Alcino al entrar en concurso amoroso con Celia? ¿Es de hecho o de derecho?

Más adelante trataremos el error de Alcino con respecto a la cosa, pero lo que en el marco jurídico perjudica a Alcino es que su error radica también en el derecho que se le ha transmitido. Alcino creía haber adquirido un derecho de propiedad, en tanto que le fue transmitido un simple derecho de uso. En este sentido, Santo Tomás de Aquino hace su aporte a lo que en el futuro será el principio de razonabilidad diciendo que “... la ignorancia de los principios universales del derecho, que todos deben saber [...] se produce por negligencia” (111). Tenemos entonces un error de derecho, por lo tanto inexcusable, que no exonera a Alcino de su responsabilidad jurídica. En el momento de transar el negocio amoroso, Alcino debió conocer la naturaleza de la transacción. La lógica de esta solución, por otra parte, se corresponde también con el famoso principio del derecho romano que reza "nemo auditur propriam turpitudinem allegare", esto es, que nadie puede alegar su propia torpeza. Por lo tanto, Alcino tampoco podría servirse de su propio error para satisfacer su petición. El fondo de la petición cae. Pero ¿qué pasa con este segundo momento, es decir, el de la reivindicación propiamente dicha?

El segundo momento lo constituye el acto jurídico del reclamo y, para que el juez pueda abocarse a considerarlo, ciertos requisitos formales deben reunirse. En efecto, el reclamo también es un acto jurídico. De resultas, para que la petición sea considerada válida, el actor debe contar con intención, libertad y discernimiento al momento de realizarla. La voz forense no opone reparos a la intención del demandante: Alcino quiere reivindicar y está reivindicando. No hay vicio que afecte la libertad tampoco: nadie está ejerciendo fuerza física sobre Alcino para que éste realice un reclamo que no quiere hacer. Sin embargo, no pasa lo mismo con el discernimiento. Por cierto, los celos de Alcino, consecuencia de su legítima desposesión, no se traducen en actos válidos jurídicamente.

${ }^{10}$ Sin embargo, es necesario aclarar que el juez que entiende en un caso debe primero verificar que la demanda cumpla con los requisitos de forma y recién después se puede abocar a considerar el contenido de la misma. 
La abogada alega que si bien Alcino era competente al momento de celebrar el negocio amoroso con Celia -lo cual lo inhabilita para alegar ignorancia en esa instancia-, su conducta al momento de reivindicar se corresponde con la de un insano y, como tal, el reclamo debería ser considerado nulo. La alusión específica a "los extremos de furioso" es muy ilustrativa en este sentido, y podemos exhumar su connotación jurídica recurriendo a la ayuda del derecho romano. En efecto, el furiosus era el hombre completamente privado de razón y, mientras durara su locura, no podía celebrar ningún acto jurídico. ${ }^{11}$ De esta manera, la voz forense impugna también la forma de la demanda de Alcino, ya que es producto de los devaneos de un loco. Los dementes, lógicamente, se encuentran impedidos de peticionar ante los tribunales por sí mismos.

En suma, para ser reputado válido, todo acto jurídico necesita de los tres elementos previamente mencionados: discernimiento, intención y libertad. Por un lado, el error de Alcino al momento de amar considerándose propietario no vicia la intención y, por lo tanto, no lo faculta a obtener un resarcimiento, ya que se trata de un error de derecho-como vimos-inexcusable. Pero aunque el fondo de este reclamo tuviera algún mérito, la petición misma de Alcino ante el tribunal invisible puede ser rechazada in limine, ya que Alcino carece de discernimiento al momento de peticionar. Quizás la desafortunada situación de Alcino a esta altura pueda ser sintetizada con las propias palabras de San Isidoro de Sevilla:

[...] se posee con derecho lo que se tiene con justicia, y se tiene con justicia lo que se tiene bien o buenamente; pues lo que se posee malamente es ajeno. Posee malamente el que usa sus cosas malamente o toma las cosas ajenas; y posee justamente el que no está dominado por la ambición o avaricia, pues el que tiene avaricia más bien se puede llamar poseso que poseedor. (118)

Bajo la premisa que sostiene que los derechos reales regulan las diferentes relaciones jurídicas que son posibles entre un sujeto y una cosa, hemos tratado en primer lugar la relación jurídica, luego el sujeto que se dice titular de la misma, y ahora nos abocaremos a trabajar con las cosas, es decir, con el objeto mismo de estos derechos reales.

Como hemos insinuado anteriormente, podemos decir que el error de Alcino recae no sólo en el derecho sino también en la cosa. Alcino ha sido usuario del amor de Celia, mientras que él, en confusión metonímica, se creyó no sólo propietario del amor, sino también de quien hacia él en su momento lo profesó. Obviamente, Alcino necesita del concurso presencial de Celia para poder ser afortunado, con lo cual podemos incursionar en el campo de las cosas materiales en sentido estricto, esto es, el cuerpo de Celia.

Si propiciáramos, entonces, una asociación a nivel poético entre posesión y acceso carnal, la primera pregunta que debemos hacernos a nivel jurídico antes de continuar es la siguiente: ¿es Celia objeto jurídico de posesión o propiedad? La respuesta que da el derecho romano, como sabemos, es afirmativa. En efecto, la posesión pacífica y continuada de una mujer por un año, por ejemplo, era uno de los modos en que el cónyuge masculino podía adquirir la famosa manus, que otorgaba al hombre el poder sobre la vida, la voluntad

${ }^{11}$ En este sentido, Santo Tomás se refiere a los insanos indistintamente como furiosos o dementes, y explica que "se llama voluntario al apetito racional y, por tanto, no puede existir en los seres que carecen de razón” (105). 
y los bienes de la mujer, cuyo estatuto jurídico equivalía al de un esclavo. ${ }^{12}$ En España y sus colonias, esta tradición jurídica permaneció casi incólume durante la Edad Media, el Renacimiento y el Barroco, en tanto que ciertos vestigios continúan hasta hoy día en diferentes regímenes jurídicos de raigambre romano-hispánica.

Sin embargo, la voz forense utiliza la materia prima de esta larga tradición para desmoronar sus cimientos. Si bien "la eterna posesión de su hermosura” podría generar una alusión ambigua a la posesión del amor y/o de la mujer, la sintaxis de esta ley poética en ningún momento pone a Celia como objeto susceptible de apropiación. El hacerlo convertiría a Celia en potencial objeto de un derecho de uso, lo cual va directamente en contra del programa sorjuanino. Por lo tanto, la voz poética, por un lado, sin dejar de apuntar en contra de las absurdas asociaciones entre mujer y objeto susceptible de apropiación, da lugar a que la voz forense interponga al amor como intermediario de las relaciones entre los dos sexos, sacando así a Celia del ámbito de las cosas que se encuentran en el comercio.

Debido a esta maniobra argumental, las cosas que están en danza como posibles objetos de posesión son, entonces, los bienes de larga tradición medieval llamados Fortuna y Amor. Podemos decir así que cuando el amor es correspondido nos muestra su lado hermoso y somos también afortunados, en tanto que cuando no es correspondido, se nos manifiesta como un sufrimiento insoportable. Haciéndose eco del "engaño colorido”, la voz poética describe a una hermosura del amor no susceptible de apropiación perenne, precisamente por su inherente carácter temporal. La voz forense, por su parte, intensifica la contundencia del argumento al insinuar un subtexto jurídico en el que la naturaleza de las cosas dicta los derechos que son aplicables a ellas: "la posesión de cosas temporales / temporal es”. En efecto, la naturaleza de las cosas manda. La casa de un particular puede ser vendida a un tercero, en tanto que la Catedral de México no. Una cantidad de dinero puede ser objeto de un mutuo, también llamado préstamo simple, mientras que un libro no. Un libro puede ser objeto de comodato, que es el contrato que todo estudiante celebra con su biblioteca. Los bienes muebles pueden ser objeto de prenda, mientras que los inmuebles lo son de hipotecas. ¿Son casuales estas rígidas relaciones de compatibilidad entre ciertos derechos y ciertas cosas? Evidentemente, la respuesta es negativa. Fue el derecho romano el régimen que legó esta organización de las cosas cuya importancia era decisiva, y se puede sostener que en gran medida tal sistema clasificatorio se ha mantenido

12 En cuanto al concepto carnal de la posesión, podemos decir que éste deviene también de una arraigada tradición histórico-jurídica. "La idea de posesión violenta es consustancial a los pueblos primitivos, que tienen que recurrir al rapto colectivo de las mujeres de los pueblos vecinos cuando no son suficientes las propias, pasando así de la endogamia o matrimonio dentro del propio pueblo a la exogamia o matrimonio con individuos de pueblos distintos. La posesión violenta se transforma en posesión pacífica al relegar el rapto a un mero rito, que todavía sobrevive en el actual 'viaje de novios'. En ocasiones se utiliza para contraer matrimonio cuando no hay consentimiento de los padres, como entre germanos, visigodos y en la Alta Edad Media. Otro tipo de posesión pacífica es la del 'uso' (usus) propia de los romanos, en los que se considera existente el matrimonio por la posesión de la mujer durante un año. Entre los romanos, se evoluciona de la compra al contrato consensual, manifestándose que 'el consentimiento crea las nupcias' (consensus facit nuptias)” (Lalinde Abadía 421-22). 
intacto hasta nuestros días. Vemos entonces que para los romanos, la clasificación más amplia de las cosas las dividía en res divini juris y res humani juris. ${ }^{13}$ Las primeras, también llamadas res nullius, no eran susceptibles de ser apropiadas por los seres humanos, ya que pertenecían a los dioses. El corolario jurídico del soneto, entonces, es que Amor y Fortuna son res nullius y, por tanto, incompatibles con el derecho de propiedad. El mensaje poético, por su parte, es que el hombre no es dueño de la mujer. Con diferentes niveles de autoridad, ambos lenguajes liberan a Celia. Con un mismo nivel de contundencia, el hombre que vindica a una mujer o al amor como si fueran una cosa (reivindicatio) es un demente. En definitiva, el famoso principio del derecho romano que establece que la cosa habla por sí misma despeja nuestros interrogantes: "res ipsa loquitur”. En el poema sorjuanino, entonces, la naturaleza misma del amor dice con lógica irrefutable que el mismo no es susceptible de apropiación. Pero detrás de la dicción del amor, están las cuerdas vocales de una mujer que se arroga para sí el derecho a decir no al asalto sobre su cuerpo. Si hasta las cosas pueden hablar por sí mismas, es de esperar que a la mujer se le adjudique tal derecho. ${ }^{14}$

En suma, los temas más aparentes del soneto son la fugacidad del amor y la impotencia de los celos para recuperarlo. Pero como hemos visto, en una suerte de cámara oculta yace un repertorio semántico al que se puede acceder usando la llave maestra de los institutos jurídicos. Así, hemos intentado hallar la combinación, restituyéndole al soneto su lenguaje cifrado por múltiples registros legales. La pregunta que nos queda por hacer es la que Paul de Man se formulaba al referirse a la alegoría: “¿por qué es que las verdades más profundas acerca del mundo y nosotros mismos tienen que ser planteadas de un modo tan referencialmente indirecto y oblicuo?” (2).

Si nos atenemos a los embates que la jerarquía eclesiástica descargó sobre Sor Juana, no creo que la respuesta pueda constituir ningún misterio. Sor Juana usurpa registros eminentemente patriarcales y los utiliza como ejes semánticos dotados de una carga estrictamente jurídica que, una vez decodificada, arroja una más entre las ácidas respuestas sorjuaninas a los estamentos hegemónicos de la sociedad colonial, en este caso, generando originales retruécanos en los que el derecho surge como hermeneuta del amor. ${ }^{15}$ Lo irónico

\footnotetext{
${ }^{13}$ De similar extracción es la distinción que hace San Isidoro de Sevilla entre las leyes divinas y las leyes humanas. "Fas (lo justo) es ley divina; ius (el derecho) es ley humana” 112.

${ }^{14} \mathrm{El}$ caso es que las cosas no hablan por sí mismas, sino que el jurisconsulto está detrás de ellas haciendo las veces de ventrílocuo. Podemos hablar entonces más de "expresar" que de "hablar," ya que el origen etimológico de esta locución (expressio) refleja más fielmente la idea de presión, de forzar algo hacia (y desde) afuera. Sor Juana reensambla a las cosas de acuerdo con una gramática jurídica diferente a la prevaleciente en el orden patriarcal para que cuando dichas cosas tengan que "hablar," lo hagan a favor de la mujer. En otras palabras, estas cosas "que hablan por sí mismas" sólo podrán articular una mera “expresión,” y así arrojar un único resultado posible que será el reflejo de la presión a la que fueron sometidas. Lo paradójico del caso es que estas cosas podrán ser vehículos expresivos en dos direcciones opuestas; por un lado, refrendando la lógica jurídica que informa los principios del derecho romano y, por el otro, traicionando las premisas ideológicas del mismo.

${ }^{15}$ El Libro de Buen Amor es un ejemplo poético temprano de la incursión del derecho en la concepción del amor y de la locura. La obra de Henry A. Kelly Canon Law and the Archprest of Hita es muy ilustrativa al respecto. Asimismo, las Cortes de Toledo en el Cantar de Mio Cid son un
} 
del asunto es que Sor Juana se apropia del lenguaje que convalida la apropiación de la mujer por el hombre para argumentar en contra de tal apropiación. Mikhail Bakhtin decía que los lenguajes no son neutrales, sino que se encuentran superpoblados de intenciones y acentos pertenecientes al hablante (35). Si es verdad que los lenguajes yacen en el borde entre lo propio y lo ajeno, Sor Juana lleva a cabo una operación expropiatoria a través de la cual emerge una revolucionaria legislación en favor de la mujer. La ironía suprema quizás sea que este cuerpo legislativo se somete a la forma de la canción amorosa por excelencia: el soneto.

Debo decir, para terminar, que encuentro mérito suficiente para continuar investigando esta vocación jurídica en la obra de Sor Juana y así descubrir nuevas lecturas que arrojen resultados no explorados previamente en su obra. Tanto la "Carta atenagórica” como la "Respuesta a Sor Filotea” son puntos de partida fundamentales para identificar los tópicos forenses en la prosa de Sor Juana. La actividad de Sor Juana como abogada defensora, sin embargo, no se limita a estas obras sino que también aparece de plano en la irónica "Petición que en forma casuídica presenta al Tribunal Divino la madre Juana Inés de la Cruz, por impetrar perdón de sus culpas,” así como también en los romances de Inundación Castálida que Méndez Plancarte clasificó como “filosófico-morales.” En resumidas cuentas, gran parte de la poética sorjuanina instala un debate en torno a los múltiples roles que la mujer debería poder desempeñar en la sociedad. Y realiza este tipo de incursiones políticas dándole a su poesía un tono jurídico, para que el hombre que compuso la ley reconozca cómo esa cacofonía de la sojuzgación puede ser transformada en una armonía de la igualdad social.

Horacio intenta trazar una línea bien clara al decir que la mediocridad puede ser tolerada en un abogado, pero nunca en un poeta. Sin duda, Sor Juana superó con creces las expectativas del padre de la poesía: en el genio sorjuanino resuenan las voces de un diálogo apasionado en el que comulgan el ya conocido magisterio poético y una eximia sofisticación jurídica. ¿¿Será verdad que, como había proclamado Percy Bysshe Shelley, los poetas son los legisladores del mundo a pesar de no ser reconocidos como tales?

Bibliografía

Abreu Gómez, Ermilo. Sor Juana Inés de la Cruz: Bibliografía y biblioteca. México: Monografías bibliográficas mexicanas, 1934.

Alfonso X. Leyes de Alfonso X. Gonzalo Martínez Díez, José Manuel Ruiz Asencio y Laura María Rubio Moreno, eds. 3v. Ávila: Fundación Sánchez Albornoz, 19851991.

Aquino, Santo Tomás de. Suma de Teología. Madrid: BAC, 1997.

Bakhtin, Mikhail. “Discourse in the Novel”. Literary Theory: An Antology. Julie Rivkin, y Michael Ryan, eds. Oxford: Blackwell, 2000. 32-44.

Benlloch Poveda, Antonio, ed. Código de derecho canónico. Valencia: Edicep, 1993.

episodio revelador de la imbricación de la actividad jurisdiccional en el desenvolvimiento de las relaciones amorosas. 
Covarrubias, Sebastián de. Tesoro de la lengua castellana o española. Martín de Riquer, ed. Barcelona: S.A. Horta, 1943.

Cruz, Sor Juana Inés de la. Inundación Castálida. [1689]. Georgina Sabat de Rivers, ed. Madrid: Clásicos Castalia, 1982.

González Echevarría, Roberto. “The Law of the Letter: Garcilaso’s Comentarios”. Myth and Archive. Durham: Duke University Press, 1998. 43-92.

Herrera Zapién, Tarcisio. "Revelación y misterio de Sor Juana”. Inundación Castálida. México: Instituto Mexiquense de Cultura, 1995.

Horacio. Arte poética. Manuel Mañas Núñez, trad. Cáceres: Universidad de Extremadura, 1999.

Jovellanos, Gaspar Melchor de. "Sobre la necesidad de unir al estudio de la legislación el de nuestra historia”. Obras en prosa. Madrid: Castalia, 1969.

Lalinde Abadía, Jesús. Derecho histórico español. Barcelona: Ariel, 1974.

Kelly, Henry A. Canon Law and the Archprest of Hita. Birghamton: Center for Medieval and Early Renaissanse Studies, 1984.

Man, Paul de. "Pascal's Allegory of Persuasion”. Allegory and Representation. Stephen Greenblatt, ed. Baltimore: Johns Hopkins University Press, 1981. 1-25.

Méndez Plancarte, Alfonso. Obras completas de Sor Juana Inés de la Cruz. Vol. 1. Lírica Personal. México: Fondo de Cultura Económica, 1951.

Muriel, Josefina. “Lo que leían las mujeres en Nueva España”. La literatura novohispana. Pascual Buxó y Arnulfo Herrera, eds. México: UNAM, 1994. 159-73.

Paz, Octavio. Sor Juana o las trampas de la fe. México: Fondo de Cultura Económica, 1983.

Perelmuter Pérez, Rosa. "La estructura retórica de la Respuesta a Sor Filotea”. Hispanic Review 51 (1983): 147-58.

Petit, Eugène. Tratado elemental de Derecho Romano. [1892]. José Ferrández González, trad. Buenos Aires: Editorial Universidad, 1999.

Sabat de Rivers, Georgina. "Veintiún sonetos de Sor Juana y su casuística del amor”. Sor Juana y su mundo. México: Universidad del Claustro Sor Juana, 1995.

Santí, Enrico Mario. “Sor Juana, Octavio Paz y la poética de la restitución”. La literatura novohispana. Pascual Buxó y Arnulfo Herrera, eds. México: UNAM, 1994. 217-30.

Sevilla, San Isidoro de. Etimologías. Santiago Montero Díaz, ed. Madrid: Biblioteca de autores cristianos, 1951. 